\title{
Evaluación de Programas de Formación de Formadores y Docentes: Estudio de Caso.
}

Núm. 2 (2014), pp. 111-153.

Antonio Medina Rivilla, Conchita Medina Domínguez¹.

JEL Clasif: I2, I21, I23.

Antonio Medina es Profesor. Director del Departamento de Didáctica, Organización Ecolar y Didácticas Especiales en la Universidad Nacional de Educación a Distancia, UNED (España) y Conchita Medina Domínguez es It Services Client Representative at IBM- España. 


\begin{abstract}
The research presented has focused on two training programs: of trainers and university teachers, contributing the assessment processes more consolidated in program evaluation, aware of the complexity of the work and impact of this evaluation on the personal and professional improvement of the professionals involved. The evaluation has estimated training needs, program design, development, global results and improvement proposals, reflecting the importance of both programs to provide: Innovative models to education professionals training; creative, tailored and relevant development of program to the expectations and demands of university teachers and trainers. Findings indicate the quality of training and professional development based on the mastery of teaching competencies of professional character; It aims to improve the research processes in the evaluation of programs, through the integration of quantitative and qualitative methods, abounding in case analysis and in the interpretation and impact of training in mastery of generic and professional competencies from students.
\end{abstract}

Keywords: Evaluation of teachers programs, integration of methods, dimensions to assess impact of a training program.

\title{
Resumen
}

La investigación presentada se ha centrado en dos programas de formación: de formadores y de profesorado universitario, aportando los procesos de valoración más consolidados en la evaluación de programas, conscientes de la complejidad del trabajo y del impacto de esta evaluación en la mejora personal y profesional de los profesionales implicados. La evaluación ha estimado las necesidades de formación, el diseño del programa, el desarrollo, los resultados globales y las propuestas de mejora, constándose la relevancia de ambos programas al aportar: Modelos innovadores para la formación de profesionales de la educación; desarrollo creativo, adaptado y pertinente del programa a las expectativas y demandas de los formadores y docentes universitarios. Los resultados evidencian la calidad de la formación y el desarrollo profesional basado en el dominio de las competencias docentes de carácter profesional; se propone mejorar los procesos de investigación en la evaluación de programas, mediante la integración de métodos cuantitativos y cualitativos, abundando en el 
Evaluación de programas de formación de formadores y docentes: Estudio de caso.

análisis de casos y en la interpretación e impacto de la formación en el dominio de las competencias genéricas y profesionales de los estudiantes.

Palabras clave: Evaluación de programas de docentes, integración de métodos, dimensiones a evaluar, impacto de un programa formativo. 


\section{Significado de la evaluación de programas formativos educativos.}

Los procesos educativos inciden en la mejora de las personas que participan en los diversos en los diversos ámbitos y modalidades formativas, aportando nuevas formas de avanzar en el pensamiento y prácticas sociales. Las tareas desarrolladas por los agentes de la educación y los sistemas formativos en general, han sido valoradas por expertos y los propios profesionales de la educación-formación, evidenciando que tales prácticas son pertinentes o han de ser revisadas y adaptadas en atención a las informaciones alcanzadas. Las acciones educativas se estructuran en programas que sintetizan los aspectos más valiosos de las realizaciones educativas, así, se destaca el significado formativo de cada programa y el posible impacto en la educación-formación de las personas/profesionales implicados en ellos.

Martínez $(2007,512)$, sintetiza la historia de la evaluación de programas en varios hitos, extrayendo los denominados:

- $\quad$ Edad tyleriana (1930-45).

- Edad de la expansión (1958-1972).

- Edad de profesionalización (1973 hasta finales del siglo XX).

- Edad del impacto y significación de evaluación de programas educativosformativos (2003 a la actualidad).

Scriven $(2003,15)$, destaca el valor de la teoría y meta teoría acerca de la evaluación, presentando algunas teorías y hasta ocho modelos de evaluación, destacando las de:

- Participación o de roles mezclados (integrados).

- Modelo director/conductor de la evaluación.

- Poder del modelo.

Scriven (2003), propugna la aplicación de multitud de modelos, dado que los contextos de evaluación son múltiples y requieren de intensas inferencias desde la observación y otros datos, que superan la mera descripción, necesaria, pero ampliada con el buen sentido común.

Se ha de buscar la raíz del significado de evaluación y de evaluación de programas formativos, objeto de esta investigación, dado que la evaluación (Scriven, 2003, 28) es 
un tipo de conocimiento que relaciona la percepción con la acción. Dada la dificultad de los juicios de valor que ha de realizar la evaluación, se requiere ir más allá de lo percibido y realizado para elaborar un conocimiento riguroso y fundamentado, llegando a ser una disciplina consolidada.

La evaluación hace referencia (Scriven, 2003, 28) y describe lo investigado en términos de valor, merito, significación, worth, que se buscan como referentes para la mejora continua.

La referencia al contexto, a consideraciones lógicas que se rigen por estándares consolidados y en relación a ellos se estima el dominio y avance en un campo de conocimiento, en relación con el cual se valora una actividad, en nuestro caso, la pertinencia y significatividad de un programa formativo, pero dando un gran valor al contexto y a los atributos de verdadero, significativo y meritorio, que ha de caracterizar lo considerado y evaluado en relación a tales atributos, se ha de considerar que la educación es una estricta disciplina, apoyada en criterios de validez científica, estricta lógica y comparable en su rigor, a otras disciplinas científicas.

La evaluación de un programa y de las prácticas sociales en general, ha de hacerse aplicando el criterio de mérito y carácter democrático y axiológico de los implicados en esta compleja tarea, estimadora del nivel de dominio de estos aspectos a considerar en el acto, programa o proceso aplicado.

La evaluación del programa formativo es un proceso de establecimiento de líneas (estándares-criterios), obtención, propiciación y aplicación descriptiva e información argumentada acerca del mérito y verdad de las metas, diseño, implantación y resultados para tomar decisiones, mayores logros, información institucionalizada y diseminación de lo logrado, para comprender mejor el acto-programa valorado (Stufflebeam, 2003, 34).

El programa ha de ser estimado en su pertinencia, impacto y evidencias de mejora alcanzados y singularmente trabajarse en las mejoras logradas durante el proceso de aplicación (satisfacción de los participantes en el programa) y logros (accountability), total de metas alcanzadas, necesidades satisfechas y resultados totales conseguidos,

Stufflebeam (2003, 35) destaca varios momentos a trabajar en los procesos formativos, singularmente en la estimación de la calidad de un programa, tales como: 
- Contexto, entradas / base de partida, proceso y resultados obtenidos.

La evaluación aporta a los responsables de las acciones y programas diseñados, los elementos que describen y justifican el valor del programa, su impacto en los participantes, la institución y los organismos públicos, privados, internacionales, etc., que se han implicado en la calidad y relevancia del programa aplicado o a aplicar.

Stufflebeam y Shinkfield $(2007,57)$ "In the ongoing development of the program Evaluation field, we believe program Evaluation approach, should be assessed and improved toward the goal of meeting the requirements of a sound theory".

La construcción de una teoría para entender la "evaluación de programas" ha de considerar (Stufflebeam y Shinkfield, 2007, 58):

- Los conceptos generales, que se concretan en: la evaluación formativa, sumativa, evaluación participativa, utilidad, meta evaluación, etc.

- Hipótesis, que orienten la investigación futura, dotándola de nuevos caminos para avanzar en el campo.

- Principios pragmáticos que orienten la tarea evaluadora, estableciendo procedimientos y reglas para la acción.

- Principios éticos, que fundamentan las decisiones en los derechos humanos, valores consolidados, ¿Qué derechos han de respetarse al aplicar la evaluación a aun programa?

El significado del impacto del programa a evaluar ha de estimarse en función a:

- Nivel de profesionalización, pertinencia del programa y capacitación de las evaluaciones para realizar esta tarea.

- Adecuación a las normas de la investigación, potencialidad del programa para incrementar el saber del campo y generar nuevas ideas.

- Planificación del proceso evaluador, cumplimiento de los procesos de evaluación y aplicación de lo pretendido en la valoración del programa.

- Definición y cumplimiento de los papeles y tareas de los implicados en la responsabilidad evaluadora.

- Cumplir la tarea evaluadora de acuerdo con los parámetros y la responsabilidad asumida, honestidad, compromiso y adecuado hacer en la práctica evaluadora. 
La evaluación de programas formativos se consolida como un ámbito esencial de la evaluación, entendida como teoría y práctica nuclear en la matriz disciplinar de la didáctica y en las ciencias sociales, de gran impacto en la transformación de las prácticas educativas. Esta práctica evaluadora se confirma como un escenario imprescindible para conocer la pertinencia de los programas para mejorar la docencia y el desarrollo profesional del profesorado.

\section{Diseño del programa para la educación de los estudiantes y el desarrollo profesional de los docentes.}

El diseño de programas es una práctica fundamental para la mejora de la educación de los estudiantes y el desarrollo profesional del profesorado. La construcción de los programas constituye una de las tareas destacadas de las administraciones educativas, las diversas organizaciones y multitud de asociaciones, que orientan su trabajo a la mejora de los seres humanos.

Sin embargo, el término programa acotado al ámbito educativo se ha definido, entre otros autores por Pérez (2006,180), un documento en el que se integran objetivos educativos, a lograr a través de determinados contenidos, con un conjunto de acciones a su servicio, entre las que incluimos la evaluación de carácter formativo, elemento que valora la pertinencia de los restantes.

El programa ha de diseñarse y tener en cuenta la complejidad del objeto del mismo, mejorar la educación de los estudiantes y en nuestro caso del profesorado. Los elementos constitutivos de un programa orientado a la mejora de las práctica educativas y de la tarea de enseñanza, son: (Pérez, 2006, 189).

- Objetivos generales, específicos.

- Contenidos (transdisciplinares, integrados).

- Métodos, medios y recursos:

- Metodología didáctica-heurística.

- Medios (TIC y clásicos). 
- Taxonomía de actividades-tareas y organización de espacios.

- Temporalización (agenda)

- Evaluación:

Diagnóstica, formativa y en su caso sumativa.

- Información de los resultados a los agentes del proceso.

- Impacto del programa en otros ámbitos.

El diseño y desarrollo del programa constituyen la base determinante de su puesta a punto, seleccionando los componentes anteriores. Al diseñar el programa se formulan de modo pertinente, cada, uno especialmente los objetivos a alcanzar, su adecuación a los variados contextos y la adaptación del resto de elementos del programa para contribuir a la consecución de tales objetivos.

El diseño es la más pertinente propuesta a alcanzar, conscientes de su valor, mérito y actualidad para conseguir la óptima formación y desarrollo profesional del profesorado, que nos proponemos alcanzar.

El diseño anticipa la pertinencia y virtualidad de su puesta en práctica, pero su desarrollo evidencia la real puesta a punto y el impacto que el programa elaborado pueda tener en la mejora del objeto del programa, dado que es la aplicación-ejecución del programa, formación de docentes y desarrollo profesional, el proceso en la acción que permite incidir en la capacitación personal y profesional del profesorado.

Determinado el diseño y puesta en práctica de un programa de formación de docentes y formadores, nos planteamos la tarea esencial de este trabajo:

¿Qué aporta la evaluación del programa a la mejora del mismo?

¿Qué investigaciones se han centrado en la evaluación de la potencialidad de los programas para la formación de docentes?

¿En que contribuye la evaluación de los programas de formación de docentes y formadores al desarrollo de la identidad y competencias docentes?

¿Qué procesos se han seguido para la mejora del desarrollo profesional del profesorado en puntos nucleares cómo?:

- ¿Creencias, metodología, prácticas reflexivas, estudio de casos, entre otros aspectos? 
La evaluación del programa de formación de docentes y formadores ha de afectar a las funciones de diseño, desarrollo y evaluación-impacto de los programas elaborados; así como a sus componentes, estructura y puesta en práctica en las más diversas situaciones formativas.

El estado de la cuestión en la evaluación de tales programas ha sido más analítico, que global, aportando esta investigación un modelo en la línea propuesta por Stufflebeam y Shinkfield (2007), centrado en una vision más integrada de los numerosos aspectos a considerar en la evaluación de los programas de formación del profesorado y formadores.

\section{El proceso de evaluación de programas de formación del profesorado y formadores.}

La valoración de programas de formación de docentes y formadores ha de atender a la estimación de la calidad de los mismos en:

- Diseño y desarrollo del programa: Diagnóstico.

Formación.

- Impacto en la formación integral: - Personal, profesional e institucional.

- Componentes del programa: Diseño Desarrollo-Resultados.

- Objetivos Diseño Desarrollo-Resultados.

- Contenidos Diseño Desarrollo-Resultados.

- Métodos, recursos/medios Diseño Desarrollo-Resultados.

- Tareas Diseño Desarrollo-Resultados.

- Organización Diseño Desarrollo-Resultados.

- Temporalización Diseño Desarrollo-Resultados. 


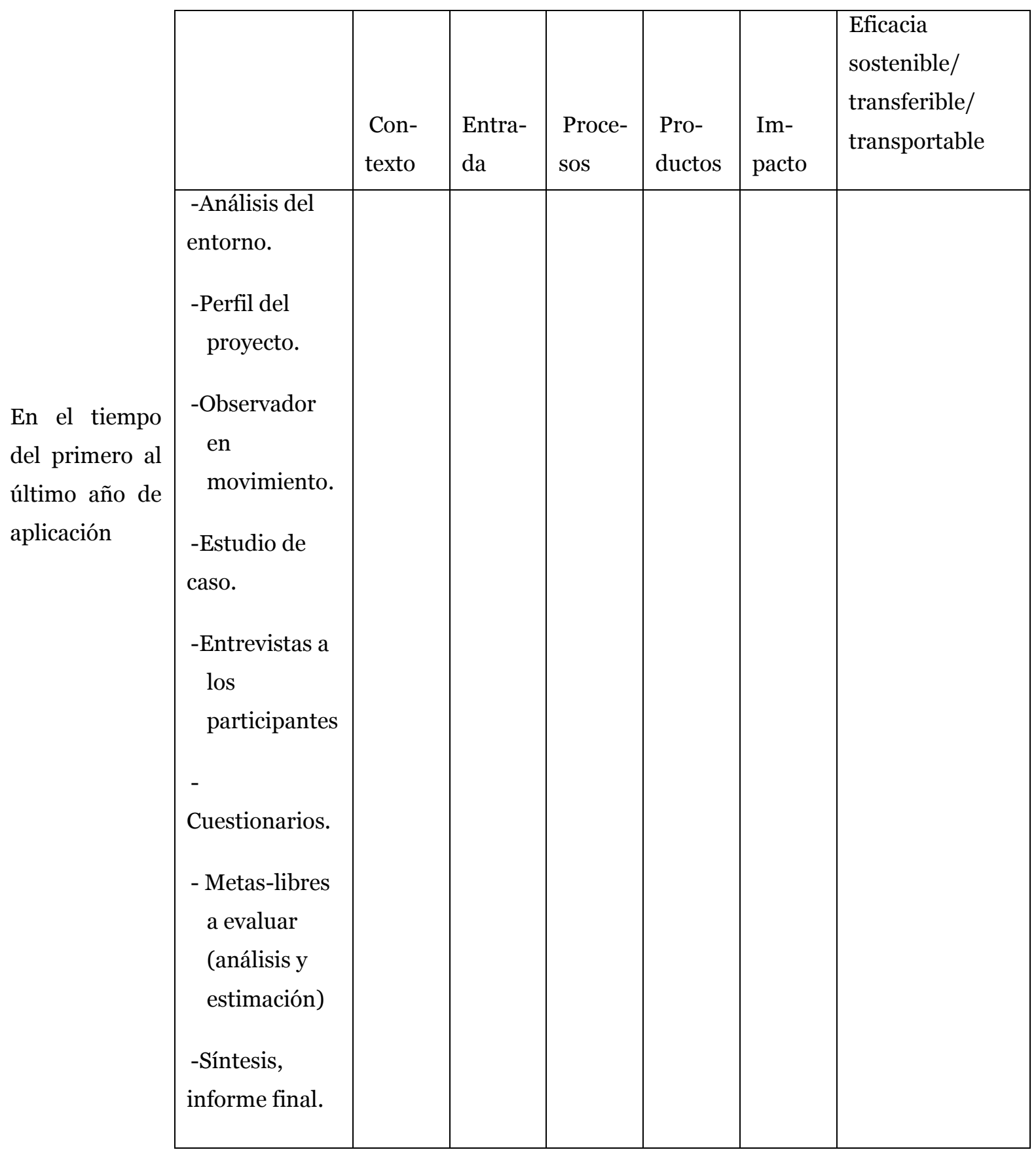

Tabla1.Métodos de evaluación (Stufflebeam y Shinkfield, 2007, 260/265).

La estimación del conjunto de elementos constitutivos del programa ha de hacerse profundizando en cada uno de ellos y considerando la pertinencia de su formulación, coherencia entre ellos y claridad conceptual.

La evaluación ha de ponderar la pertinencia, actualidad, factibilidad e impacto de cada componente del programa, su estructura y la armonía global del mismo, así como 
la adecuación para alcanzar los objetivos pretendidos y mejorar su impacto en los participantes, instituciones y procesos de enseñanza-aprendizaje.

La evaluación del programa se ha de realizar en las situaciones previas a su aplicación, diagnóstico de necesidades, expectativas y requisitos personales e institucionales para conocer las posibilidades del programa en la adecuación y formulación de cada uno de sus elementos a las personas y realidades de las que se espera que sean auténticos beneficiarios.

La evaluación de los programas de formación de docentes ha de centrarse en los aspectos esenciales que inciden en la transformación y en el desarrollo profesional de aquella; así al evaluar la potencialidad formativa de un programa para el profesorado y los formadores han de considerarse los elementos que constituyen las bases para el avance personal, profesional e institucional de cada participante en el programa y el impacto que tal formación se espera que logre en la educación integral de los estudiantes y en la innovación de los procesos de enseñanza-aprendizaje.

La complejidad de esta pretensión trasciende la vision clásica de centrar la evaluación en el diseño y desarrollo del programa, especialmente del enfoque más consolidado, consistente en aportar nuevos conocimientos más ligados a ofrecer informes, que evidencian la adecuación de un programa en curso a la mejora de la formación del profesorado y de los formadores.

El valor de esta investigación radica en encontrar lo más valioso de la evaluación de algunos programas en los que hemos, participado, ligados especialmente, el primero (1991, Formación de formadores para el empleo de Tic), centrado en la formación basada en: "autoaprendizaje, autoanálisis de biografías formativas, apoyo de expertos, diseño de tareas y procesos de innovación didáctica personales y en equipo, evidencias de estudio de caso desarrollados en interacción con nuevos equipos de formandosdocentes (Proyecto Fondo Social europeo-UNED. Centros asociados de Uned 3). (Medina y Domínguez, 1991).

Evaluación de la función docente y análisis de programas de formación de docentes desarrollados por el Instituto de Evaluación de la Educación y el análisis de programas de formación de docentes en las Instituciones Universitarias (1992-98), que evidencia: 
- Necesidad de modelos más consolidados de formación de docentes.

- Identificación de nuevos elementos que definan la función docente de calidad.

- Selección de las aportaciones que consolidan una línea permanente de mejora de la función docente.

- Elaboración de programas, en el ámbito universitario, comprometidos con la formación didáctica: inicial y permanente del profesorado.

- Complementariedad entre modelos centrados en la formación inicial y continua del profesorado.

(Publicación del INEC, 1997 y Medina y Rodríguez, 1998).

La evaluación de programas de formación de docentes universitarios, ligados a la capacitación de profesionales en el dominio de las competencias docentes, que ha puesto de manifiesto:

- La importancia de diseñar un modelo que identifique las competencias docentes más valoradas por el profesorado.

- El análisis de las prácticas docentes universitarias y su impacto en el desarrollo profesional del profesorado.

- La complementariedad entre métodos cuantitativos y cualitativos para avanzar en programas de formación.

- Intensidad e impacto que la formación por competencias, tanto docentes como discentes, está significando para el profesorado universitario.

- Interés de la actualización y el desarrollo profesional de los docentes universitarios.

- Proyección de la formación por competencias en los programas de formación de formadores en las empresas.

(Proyectos de estudio y análisis, 2006-2007; Proyecto AECI, 2012 coordinados por Medina y la investigación de Medina Domínguez, 2012).

Las investigaciones presentadas, se amplían con las elaboradas por Tejada y cols (2013); Marcelo (2013); Mas y cols (2013), que coinciden en subrayar para docentes y formadores, el reto de dominar las competencias docentes, en la diversidad de modalidades formativas, presencial, a distancia, e-learning, mezclada, etc. 
Evaluación de programas de formación de formadores y docentes: Estudio de caso.

Las aportaciones coinciden en la necesidad de realizar balances bianuales o cuatrimestrales para avanzar en los hallazgos más destacados en la tarea compleja de la formación de docentes y formadores, tanto en su capacitación inicial (pre-service), como en la permanente (in- Service), generando una línea de innovación e investigación en la formación de docentes-formadores (Day y Ong, 2012; DeVries, Van de Grift y Jansen, 2013; Medina de la Herrán y Domínguez, 2013; Medina, Pérez y Campos, 2014), que retoman los modelos más pertinentes para la formación continua de los docentes, dado que los programas de formación han de sintetizar las perspectivas y enfoques más valiosos aportando nuevos contenidos y resumiendo las más destacadas formas de preparación y desarrollo profesional de los implicados en el diseño y desarrollo de tales programas. Así, proponemos una síntesis de procesos formativos basados en:

- Narrativas y autobiografías del profesorado, sustentadas en experiencias formativas relevantes, gratificantes e innovadoras.

- Tareas basadas en la colaboración entre colegas y el trabajo en equipo.

- Procesos de construcción de saberes profesionales basados en estudios de caso reflexivos, longitudinales y colaborativos.

- Compartir concepciones, creencias y procesos mentales proyectados a la mejora de la práctica y al análisis de nuevas formas de entender nuestros estilos docentes y la interacción didáctica.

- Integrar diversas opciones y métodos didácticos y heurísticos para avanzar en modelos de innovación e investigación de la docencia.

- Desarrollo profesional basado en el dominio de las competencias docentes y uso creativo de Tic.

- Diálogo y encuentro entre culturas profesionales y sociales. 


\section{Problema de investigación: Modelo de evaluación de programas de formación de docentes y formadores.}

La investigación se centra en construir y aplicar algún modelo de evaluación de la calidad de los programas de formación, preferentemente continua (in-service) del profesorado y formadores, que desempeñan su docencia en la Educación superior, por su proyección en el resto de los docentes de los sistemas educativos.

El contexto en el que se diseñan y aplican los programas de formación de docentes es la universidad respectiva, mediante el enfoque de actualización y desarrollo profesional, prioritariamente focalizado en el dominio de las competencias.

Las preguntas nucleares son: ¿Disponen las universidades de modelos de evaluación de la formación de los docentes que valoren la incidencia de tal formación, en su mejora personal, profesional e institucional? ¿Se ha consolidado en las universidades implicadas procesos de evaluación de la calidad de los programas de formación de formadores?

La línea de investigación ha de explicitar el camino más pertinente para identificar y fundamentar algún modelo que propicie la evaluación de la potencialidad formativa y transformadora de los profesionales de la docencia y de la formación en la educación universitaria y en las instituciones productivas, profundizando en la sintonía entre los modelos y procesos evaluativos (métodos, técnicas y acciones), que pongan de manifiesto la adecuación de las concepciones y prácticas evaluadoras para consolidar programas pertinentes para el desarrollo profesional del profesorado.

Stake (2013); Tiana, (2013); Medina y cols (2013); Medina Domínguez (2012); Martínez (2011), expresan que la evaluación ha de entenderse como una concepción y tarea orientada al conocimiento, mejora y transformación de la acción educativa valorada, atendiendo a la complejidad de la misma, la multitud de factores que inciden en el programa y la necesidad de identificar lo más valioso de éste. 
Evaluación de programas de formación de formadores y docentes: Estudio de caso.

La evaluación del programa ha de aportar los conocimientos adecuados para entenderla y propiciar las bases para la transformación y mejora continua de los procesos formativos aplicados al desarrollo profesional permanente del profesorado.

\section{Objetivo General.}

Diseñar algún modelo para la evaluación de la calidad de los programas de formación de docentes y formadores en el marco universitario y de las organizaciones productivas.

\section{Objetivos Específicos.}

- Descubrir los componentes esenciales que han de valorarse para comprender y mejorar la calidad de los programas de formación de formadores.

- Aportar los elementos más valiosos que han de valorarse para estimar la calidad de los programas de formación de formadores.

- Construir las bases para diseñar un modelo de evaluación de la calidad de programas de desarrollo profesional de los docentes universitarios.

- Integrar los componentes comunes a la evaluación de programas de desarrollo profesional de docentes y de formadores.

- Plantear líneas futuras de diseño y desarrollo de programas para la actualización y desempeño profesional del profesorado y los formadores/as.

\section{Claves para comprender la evaluación de los programas de formación de docentes y formadores desarrollados.}

La evaluación de los principales programas, que analizamos, en visión de Stufflebeam y Shinkfield $(2007,650)$, será un proceso reflexivo; cercano a la meta evaluación de los programas valorados y de su incidencia en la construcción de un modelo-metodología adaptada a la mejora de los programas realizados.

La construcción de un modelo de evaluación de programas ha de responder a los objetivos y al proyecto de innovación que se propone lograr, de tal modo, que la formación constituye el núcleo de la evaluación del programa. Se requiere que el 
evaluador asuma y conozca los más relevantes que se han desarrollado en la historia de la didáctica, ampliados con los enfoques más significativos, actualmente integrados por las visiones del auto aprendizaje, la colaboración, el enfoque actualizado del pensamiento y el dominio de las competencias docentes.

Comprender la evolución de los procesos formativos más relevantes, consolidados en las dos últimas décadas, que han tenido lugar en el contexto universitario, ligado a numerosas universidades que armonizan la educación presencial y a distancia, conscientes de la importancia del contexto, el valor de los recursos aplicados y la construcción de un clima propicio al desarrollo profesional del profesorado.

Incorporar al profesorado al diseño y desarrollo del programa formativo, partiendo de las expectativas y requisitos de actualización profesional, conscientes de las necesidades que demandan la docencia y los retos de las nuevas titulaciones.

Armonizar los procesos de centro con los de coevaluación, ampliados con procesos de heteroevaluación, generando procesos de triangulación que incrementan la validez y consolidación de las diversas formas y modalidades evaluativas.

La evaluación del programa de formación de formadores se ha realizado con la colaboración de expertos y complementada con procesos de triangulación metodológica de personas (docentes, estudiantes - docentes y expertos), modalidades evaluativas, auto, co y heteroevaluación y métodos y técnicas en complementariedad: cuestionarios ad hoc, grupos de discusión y observación de los procesos formativos, presentados en artículos, obras básicas y diseño generalizado del modelo y aplicado en nuevos programas formativos y realización de tareas innovadoras para el desarrollo profesional del profesorado y formadores.

Hemos integrado el modelo de formación como complemento esencial de los programas de formación desempeñados, en el caso de los europeos por prescripción de la normativa y en el caso de AECI, por exigencia de las universidades implicadas y de la Agencia española, aplicando la modalidad de evaluación formativa durante el proceso de desarrollo del programa y la sumativa al culminar los procesos en su globalidad. 
La implicación de todos los participantes en el programa, se ha visto reflejada en una rigurosa actuación de auto y coevaluación, que ha facilitado el conocimiento de las prácticas formativas y se ha visto reflejado en la toma de decisiones, durante la aplicación del programa, evidenciándose en continuas mejoras, ampliadas con valoraciones complementarias reflejadas mediante:

- La aplicación de algunos cuestionarios ad hoc que ponen de manifiesto las opiniones de los participantes, acerca de la pertinencia y repercusión real del programa en la capacitación de los formadores/docentes que lo comparten.

- Proyección e impacto de la formación alcanzada en la preparación de los estudiantes, razón final de la capacitación del profesorado y formadores.

\section{Proceso de investigación en complementariedad de métodos cuantitativos y cualitativos en la evaluación.}

La evaluación de un programa formativo es una actividad rigurosa y fundamentada, que se apoya en modelos, criterios y pruebas contrastadas de carácter heurístico.

En coherencias con los métodos aplicados a la evaluación de programas (Pérez, 2006; Stufflebeam y Shinkfield, 2007; Martínez, 2011; Medina y Villar, 1995; Medina, 2003; Ibáñez y cols, 2008), entre otras investigaciones se constata que la realización de la tarea de evaluación de programas es en sí una forma científica de valorar la potencialidad y calidad de tal programa.

Los métodos aplicados en la evaluación de los programas de formación realizados han sido de integración cuanti- cualitativos.

La evaluación del programa de formación de formadores (Fondo Social EuropeoUNED, Medina y Domínguez, 1991) se llevó a cabo mediante la complementariedad de métodos cuantitativos, cuestionario adaptado durante el bienio de puesta a punto y desarrollo del programa, aplicado por mandos, formadores, expertos - investigadores y administración del programa. 
El diseño de los diversos cuestionarios, con una base común, se llevó a cabo mediante el método de Delphi, el diálogo, juicio, acuerdo y síntesis de las aportaciones de los expertos, realizándose la necesaria validez de contenido y configurado el modelo del cuestionario coherente con el de formación de formadores, adaptado a las necesidades de los formandos/futuros formadores, a las orientaciones del Fondo Social Europeo, normas de la Comisión técnica especializada y a los criterios de búsqueda, innovación y mejora continua, que caracterizan las directrices de esta modalidad de programas.

Se completó el enfoque cuantitativo con el cualitativo, aplicando protocolos para la autoevaluación y el desarrollo de micro grupos (de 4 a 7 miembros), empleando grupos de discusión para estimar la calidad del proceso de formación realizado.

Se completan los métodos con la observación participante y elevado protagonismo de todos los implicados, mediante la utilización de cuadernos de campo, escala de observación y registro de incidentes críticos.

Este proceso de triangulación metodológica constituyó la base para realizar la evaluación de la función docente del grupo correspondiente, presidido por el Dr. Ibáñez (1997 -98), que realizó un extenso estudio en numerosas comunidades autónomas (más de 10) para valorar y tomar decisiones de mejora en la realización de las prácticas docentes llevadas a cabo durante el citado bienio, constituyéndose un cuestionario "ad hoc", que fue respondido por una amplia y representativa muestra del profesorado de ESO, cuya finalidad era evidenciar la pertinencia de la formación y del proceso docente desempeñado para lograr los objetivos pretendidos en la Educación Secundaria Obligatoria (ESO) y comprender el reto de las culturas formativas e identidad profesional del profesorado.

Martínez (2010, 214/215), propone la aplicación del principio de complementariedad metodológica, empleándose una gran variedad de métodos, ya sean cuantitativos, observación participante, grupos de discusión, entrevistas, ampliados con los cuantitativos: observación sistemática, pruebas de rendimiento, cuestionarios, etc.

La evaluación del programa ha de tener en cuenta los siguientes componentes: 
Dimensiones

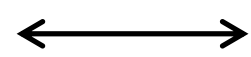

Métodos.

\begin{tabular}{|l|l|}
\hline - Análisis de necesidades. & Análisis, entrevistas, observaciones, etc. \\
\hline - Conceptualización y estructura & $\begin{array}{l}\text { Análisis del contenido y comparación con } \\
\text { otros programas. }\end{array}$ \\
\hline - Planificación de la puesta en & $\begin{array}{l}\text { Análisis del contexto, evaluación de la } \\
\text { planificación, comparación con criterios. }\end{array}$ \\
\hline acción. & $\begin{array}{l}\text { Observación, cuestionarios, entrevistas, } \\
\text { Análisis de los procesos. }\end{array}$ \\
& $\begin{array}{l}\text { Comparación de criterios, evaluación de la } \\
\text { satisfacción, diseños cuasi- experimentales, } \\
\text { etc. }\end{array}$ \\
\hline Análisis de resultados. & Informe global, impacto futuro \\
\hline & \\
\hline
\end{tabular}

Tabla 2. Componentes de la evaluación de programas (Martínez, 2010, 215/216)

La aplicación de esta metodología de los componentes/fases de evaluación del programa ha de realizarse atendiendo a las normas consensuadas por el Joint Committee on Standards for Evaluation (Yarbrough et al. 1994), que se sintetizan en:

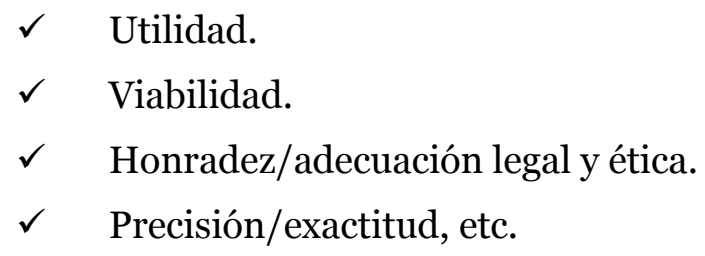

Stake $(2013,307)$, profundiza en tres cuestiones a tener en cuenta por los agentes evaluadores:

\footnotetext{
$\checkmark \quad$ Estandarización de programas.

$\checkmark$ Imparcialidad.

$\checkmark \quad$ Desarrollo personal, que se han de completar con la complejidad, justificación de las conclusiones y la meta evaluación (perfección continua del proceso evaluador).
} 
Stake $(2013,314)$, plantea que el proceso de estandarización ha de tener en cuenta:

$\checkmark \quad$ ¿Qué fuentes los fundamentan? (ISO, otros manuales.).

$\checkmark \quad$ ¿A quién importa? (Docentes, administración, etc.).

$\checkmark \quad$ ¿Qué métodos? (Medición, comparación, etc.).

$\checkmark \quad$ ¿Qué historias? (Narrativa seleccionadas, biografías, etc.).

$\checkmark \quad$ ¿Qué problemas? (Relevancia, imparcialidad, estándares, etc.).

$\checkmark \quad$ ¿Qué virtudes? (Comunicación, eficiencia imparcialidad, etc.).

La metodología esencial en la valoración de la calidad de un programa de formación de docentes y formadores, Es Estimar el Sentido de Calidad (Diseño del Programa), Su Metodología Didáctica para el Desarrollo y Convertir el Programa en un Auténtico Proceso para la Identidad Profesional de Cada Docente, Equipos, Claustros, Miembros de la Misma Institución, Integrando el Dominio de los Saberes en las Competencias Docentes con el Compromiso de la Investigación de la Docencia y de los Valores de la Educación Integral. (Implicación de 4 formandos y 20 expertos investigadores).

\section{Evaluación y análisis de los resultados del programa de formación de formadores, culminado en 1991 (F.S.E -UNED).}

La perspectiva histórica, las publicaciones y artículos elaborados nos facilitará la evaluación demorada del programa y el impacto en los diversos equipos de los centros asociados de: Ávila, Valdepeñas, Mérida y Madrid, con especial referencia en los profesionales -formandos capacitados, expertos implicados, gestores de centros asociados e investigadores internacionales, procederemos a su evaluación: 


\begin{tabular}{|c|c|c|}
\hline $\begin{array}{c}\text { Detección de } \\
\text { necesidades del } \\
\text { contexto, formandos, } \\
\text { formadores y expertos }\end{array}$ & Métodos y técnicas & Resultados \\
\hline $\begin{array}{c}\text { - Actualización del } \\
\text { pensamiento y práctica } \\
\text { reflexiva de la docencia. } \\
\text { - Dominio de la } \\
\text { competencia digital. } \\
\text { - Asumir las } \\
\text { responsabilidades de la } \\
\text { formación y su impacto en las } \\
\text { comunidades. } \\
\text { - Identificación con la } \\
\text { función del formador de } \\
\text { formadores: } \\
\text { - Conocimiento y } \\
\text { desarrollo de programas del } \\
\text { Fondo Social Europeo. } \\
\text { - Creación de una } \\
\text { cultura de superación y de } \\
\text { mejora de las personas y } \\
\text { comunidades. } \\
\text { - Investigación y } \\
\text { cormadon imores innovadores grupos de } \\
\text { conbitos. }\end{array}$ & $\begin{array}{c}\text { - Cuestionarios. } \\
\text { - Entrevistas. } \\
\text { - Normativa europea } \\
\text { (análisis de contenido). } \\
\text { - Grupos de discusión. } \\
\text { - Observación } \\
\text { participante. } \\
\text { - Armonización } \\
\text { de métodos } \\
\text { didácticos y } \\
\text { heurísticos. } \\
\text { - Autobiografías. } \\
\text { - Co-biografías. } \\
\text { formación e impacto en } \\
\text { otros niveles del sistema } \\
\text { educativo. } \\
\text { - Estudio de caso. } \\
\text { - Trabajo en equipo. } \\
\text { - Aprendizaje autónomo } \\
\text { y a lo largo de la vida. } \\
\text { - Proyectos para }\end{array}$ & $\begin{array}{c}\text { - Creación de programas } \\
\text { innovadores. } \\
\text { - Desarrollo de co- } \\
\text { biografías basadas en } \\
\text { experiencias relevantes. } \\
\text { - Diseño de un modelo de } \\
\text { integración del ordenador en } \\
\text { los procesos de enseñanza- } \\
\text { aprendizaje. } \\
\text { - Generación de nuevas } \\
\text { prácticas para desarrollar } \\
\text { actitudes y valores creativos en } \\
\text { los formadores. } \\
\text { - Asentamiento de equipos } \\
\text { de formadores innovadores. } \\
\text {-Dominio de métodos } \\
\text { cualitativos de investigación. }\end{array}$ \\
\hline
\end{tabular}




\begin{tabular}{|c|c|c|}
\hline $\begin{array}{c}\text { Diseño del programa de } \\
\text { formación de } \\
\text { formadores }\end{array}$ & Métodos & Resultados \\
\hline $\begin{array}{l}\text { Definición de las metas y } \\
\text { objetivos a alcanzar. } \\
\text { - Conocer los procesos de } \\
\text { autoaprendizaje. } \\
\text { - Realizar bio-gramas, que } \\
\text { expresen el modelo de } \\
\text { formación de formadores. } \\
\text { - Aplicar los programas de } \\
\text { ordenador más pertinentes a } \\
\text { grupos de estudiantes elegidos. } \\
\text { - Crear algún modelo de } \\
\text { formación de formadores. } \\
\text { - Implicarse en la mejora de } \\
\text { los procesos de aprendizaje a lo } \\
\text { largo de la vida. }\end{array}$ & $\begin{array}{l}\text { - Análisis de contenido del } \\
\text { programa. } \\
\text { - Comparación del } \\
\text { programa con otros aplicados } \\
\text { en contextos similares. } \\
\text { - Diseño de modelos de } \\
\text { programas en condiciones } \\
\text { semejantes. } \\
\text { - Trabajo en equipo y } \\
\text { ponderación de competencias } \\
\text { y objetivos. } \\
\text { - Aplicación de bio- } \\
\text { gramas y transferencia de } \\
\text { objetivos a otros programas } \\
\text { similares. }\end{array}$ & $\begin{array}{c}\text { - Elaboración del programa a } \\
\text { seguir para alcanzar los objetivos } \\
\text { previstos. } \\
\text { - Toma de conciencia del } \\
\text { valor del auto-aprendizaje. } \\
\text { - Elaboración de unidades } \\
\text { didácticas y diseños de formación } \\
\text { innovadores. } \\
\text { - Consolidación de una línea } \\
\text { innovadora de diseño de tareas } \\
\text { para la formación integral de los } \\
\text { formandos. }\end{array}$ \\
\hline
\end{tabular}


Evaluación de programas de formación de formadores y docentes: Estudio de caso.

\begin{tabular}{|c|c|c|}
\hline $\begin{array}{c}\text { Aplicación y desarrollo del } \\
\text { programa }\end{array}$ & Métodos & Resultados \\
\hline $\begin{array}{l}\text { - Elaboración de un modelo de } \\
\text { auto-aprendizaje a partir de las } \\
\text { experiencias profesionales más } \\
\text { relevantes de los participantes. } \\
\text { - Construcción de un proceso de } \\
\text { formación basado en experiencias } \\
\text { determinantes de la historia } \\
\text { profesional. } \\
\text { - Debate en torno a diversos } \\
\text { enfoques y programas de formación, } \\
\text { de formadores, síntesis entre el } \\
\text { modelo inductivo personal y la } \\
\text { elección de modelos teóricos } \\
\text { fundamentados. } \\
\text { - Diseño de unidades didácticas } \\
\text { innovadoras apoyadas en el empleo de } \\
\text { nuevos programas y en uso creativo } \\
\text { del ordenador. } \\
\text { didácticos y de investigación en el } \\
\text { desarrollo de un perfil creativo de } \\
\text { formador/ra. } \\
\text { - Desarrollo de prácticas } \\
\text { centros eduidualizadas y en equipo, } \\
\text { - Integración de mótodos }\end{array}$ & $\begin{array}{c}\text { - Armonía de métodos } \\
\text { didácticos y heurísticos. } \\
\text { - Se evalúa la coherencia } \\
\text { entre el diseño y el desarrollo } \\
\text { de procesos de innovación de } \\
\text { la formación de formadores. } \\
\text { - Observación } \\
\text { participante. } \\
\text { - Estudio de caso. } \\
\text { - Trabajo en parejas y en } \\
\text { pequeño equipo. } \\
\text { - Aprendizaje basado en } \\
\text { problemas. } \\
\text { - Pre-test, post-test, } \\
\text { cuestionarios, pruebas ad hoc. } \\
\text { - Elaboración y análisis de } \\
\text { materiales didácticos. } \\
\text { - Diseño innovador de } \\
\text { soft-programas. } \\
\text { - Cultura de colaboración. }\end{array}$ & $\begin{array}{c}\text { - Configuración de un } \\
\text { modelo de formación de } \\
\text { formador personalizado. } \\
\text { - Creación en equipo del } \\
\text { modelo y programas de } \\
\text { formación. } \\
\text { - Desarrollo de una línea } \\
\text { de avance profesional, } \\
\text { individualizado y en equipo. } \\
\text { - Construcción de un } \\
\text { proceso de diseño de } \\
\text { unidades didácticas basado } \\
\text { en el uso de tecnologías } \\
\text { apoyadas en el ordenador y } \\
\text { nuevos softs, } \\
\text { experimentados en las } \\
\text { diversas áreas curriculares. }\end{array}$ \\
\hline
\end{tabular}

Tabla 3. Evaluación y análisis de los resultados del programa de formación de formadores. (F.S.E. - UNED, 1991) 


\section{Análisis de resultados globales e impacto del programa.}

Los resultados globales se evalúan aplicando los criterios de complejidad. Ética, viabilidad y adecuación de las normas del Fondo Social Europeo y de los criterios de rigor pertinencia y calidad, que caracterizan los programas de formación y singularmente los de profesorado y formadores.

El programa ha aportado un modelo de formación de formadores adaptado al reto del uso de las Tic, que sirvió de base para el diseño y desarrollo de numerosos proyectos y cursos de capacitación de formadores en diversas universidades, administraciones públicas y direcciones de recursos humanos de varias empresas.

Orientó una línea de Doctorado, diseño de tesis doctorales y abundantes publicaciones, con gran impacto de Congresos nacionales e internacionales, así como en la consolidación de un grupo interuniversitario e internacional de Formación como base para el desarrollo de las Comarcas (1996/7-2008), que continua con un enfoque internacional y de diálogo entre culturas, por ejemplo el Proyecto en Juan y Medio, Riohacha-Colombia (Ruiz y Medina, 2014).

El modelo integra:

- Aprendizaje autónomo basado en bio y co-biografías de experiencias relevantes, completado con el aprendizaje colaborativo, trabajo intenso en parejas y equipos de colaboración entre cuatro y cinco componentes.

- Diseñar unidades didácticas innovadoras incorporando el uso de ordenadores, diseños instructivos y soft creativos, impulsores de la cultura de la innovación.

- Aplicación de unidades didácticas y valoración del impacto de los modelos tecnológicos en los procesos de enseñanza-aprendizaje.

- Consolidación del equipo nacional e internacional de formación de formadores/as basado en la complementariedad de experiencias formativas entre Alemania, Bélgica-Lieja, España, México y Colombia, que sirvió de base a nuevos proyectos en los respectivos países y ha consolidado una renovada línea con intensa proyección en actualizados modelos de formación de formadores, apoyados en el dominio de las competencias genéricas y profesionales. 
- El impacto del modelo en las administraciones educativas, creando programas pertinentes que preparaban a otros docentes en los aspectos educativos y en la solución de problemas más relevantes que tienen planteados jóvenes, personas adultas y docentes en general, quienes requieren del apoyo de expertos y de su propia iniciativa para aprender de su práctica y convertirla en estudio de caso a indagar, construir procesos innovadores y aplicar a las más diversas realidades la tecnología adecuada, llevando a cabo un uso didáctico del ordenador, contribuyendo a diseñar nuevos softs, diseños adaptados de unidades formativas, etc.

- Impulso y consolidación de una metodología integrada heurística y didáctica, que ha servido de base para diseñar programas de formación de formadores/as y docentes (Medina, 2011), sintetizados en la integración de autobiografías, trabajo colaborativo, estudio de caso, auto-análisis, observación personal y en equipo, grupos de discusión y análisis del contenido de las prácticas y discursos construidos en los procesos de enseñanza-aprendizaje llevados a cabo.

\section{Propuestas de mejora.}

La evaluación evidencia que el programa ha de seguir mejorándose en sucesivas investigaciones, singularmente en el concepto de formación y desarrollo, que aglutino un grupo interuniversitario, relacionado con programas de transformación comarcal, afianzando la capacitación de los formadores/as líderes implicados en la mejora de las comunidades.

La línea de adaptación de la tecnología y el uso creativo de la misma en los programas de formación docente ha sido ampliada y trabajada en consonancia con el impacto de las Tic en los procesos de enseñanza-aprendizaje, ampliada la vision de la formación y valorando la adecuación e integración de los medios en la innovación de las acciones educativas.

La evaluación del programa en su proyección en los formandos y estudiantesdocentes implicados ha evidenciado que se requirió mejoras en las modalidades formativas, la integración de las Tic en los procesos instructivos y en el desarrollo de prácticas, que constituyeran estudios de casos, que impulsaran más singularmente la investigación de las prácticas docentes. 
Se propone avanzar en la adaptación del programa a las demandas de nuevos enfoques científicos y tecnológicos, redescubriendo el sentido de las concepciones y prácticas educativas para atender a las continuas transformaciones, que requiere la docencia en un mundo complejo, incierto y profundamente interdependiente.

Los contextos universitarios han de adecuarse a los permanentes retos, especialmente integrar la tecnología en una visión de la formación abierta y creativa en diálogo con todas las culturas.

El programa ha de mejorar la optimización de los recursos, el tiempo y la intensidad de las tareas en las que se implican los formandos-estudiantes incrementando la relación entre la formación teórico-práctica y el desempeño de la docencia.

El programa realizado durante más de un bienio mejoró la cultura de la formación de numerosos investigadores, docentes en ejercicio, formadores participantes en acciones con jóvenes y personas adultas, e influyó en la cultura institucional con una elevada repercusión en los procesos educativos, de la universidad, los centros asociados colaboradores y los profesionales de UNED y de las restantes universidades, creando las bases de una cultura de innovación e investigación de la formación para la capacitación de todas las personas.

La valoración de los cuestionarios, entrevistas y grupos de discusión evidencia una alta estimación del programa, por todos los participantes del programa, destacando la incidencia en los formadores capacitados, la consolidación de una cultura de investigación e innovación de la formación de formadores, al mejorar el programa mediante la aplicación de auto-evaluaciones y co-evaluaciones trimestrales y la incorporación al desarrollo del programa de las mejoras sugeridas, integrando aportaciones derivadas de la metodología empleada: encuestas, de opinión, grupos de discusión, narrativas, observación perseverante y entrevistas en profundidad; que constataron el logro de los objetivos del programa, la movilidad de jornadas semestrales en las sedes de trabajo, culminando la Jornada de mayor impacto-final en el centro asociado de Ávila, coincidiendo con la finalización del proyecto. 


\section{Evaluación del programa - proyecto de innovación de la formación del profesorado universitario para mejorar las competencias docentes.}

Este programa se ha culminado en 2013, mediante el apoyo de AECI. La evaluación de la pertinencia de este programa de formación de docentes en cinco universidades (IUNIR- Rosario, ESPE- de Quito y Unison de México), además del diagnóstico del modelo de formación de docentes universitarios, con carácter piloto del programa, mediante estudios de caso, Jornadas, ad hoc y reflexión corporativa en el diseño y desarrollo del programa (Medina y cols, 2013).

La evaluación de este programa de formación de docentes, evidencia, siguiendo las bases y acciones similares a las realizadas anteriormente, los siguientes aspectos e informe final:

\begin{tabular}{|c|c|c|}
\hline $\begin{array}{l}\text { Detección de } \\
\text { necesidades }\end{array}$ & Métodos & Resultados \\
\hline $\begin{array}{c}\text { - Identificación de las } \\
\text { competencias docentes más } \\
\text { demandadas por el profesorado. } \\
\text {-Diseño del mapa de } \\
\text { competencias adecuado a las } \\
\text { innovaciones didácticas de las } \\
\text { universidades. } \\
\text {-Elaboración de un programa } \\
\text { para el desarrollo profesional del } \\
\text { profesorado universitario. }\end{array}$ & $\begin{array}{c}\text { Diagnóstico: } \\
\text { - pretest. } \\
\text {-Encuestas: (cuestionario ad } \\
\text { hoc). } \\
\text {-Análisis de planes de las } \\
\text { nuevas titulaciones. } \\
\text {-Entrevistas. } \\
\text {-Grupos de discusión. } \\
\text {-Observación participante. } \\
\text {-Narrativas de dominio de } \\
\text { alguna competencia. }\end{array}$ & $\begin{array}{c}\text {-Construcción del mapa } \\
\text { de competencias docentes } \\
\text { más valoradas. } \\
\text {-conocimiento del nivel } \\
\text { de dominio de las } \\
\text { competencias docentes más } \\
\text { estimadas por el } \\
\text { profesorado. } \\
\text {-Elaboración de un } \\
\text { programa de formación y } \\
\text { desarrollo de las } \\
\text { competencias docentes. } \\
\text {-Grupos de trabajo } \\
\text { compartido. }\end{array}$ \\
\hline
\end{tabular}




\begin{tabular}{|c|c|c|}
\hline $\begin{array}{l}\text { Diseño del programa de } \\
\text { formación }\end{array}$ & Métodos & Resultados \\
\hline $\begin{array}{c}\text { - Definir las competencias } \\
\text { docentes a formar (planificación, } \\
\text { comunicación...). } \\
\text { - Formular los objetivos a } \\
\text { alcanzar. } \\
\text { - Establecer el conjunto de } \\
\text { competencias más relevantes } \\
\text { para el desempeño de la } \\
\text { instrucción en la institución } \\
\text { universitaria. } \\
\text { - Generar situaciones } \\
\text { prácticas innovadoras, que } \\
\text { evidencien dominio de las } \\
\text { competencias. } \\
\text { - Construir una cultura de } \\
\text { prácticas docentes innovadoras } \\
\text { previas. } \\
\text { compromiso del profesorado con } \\
\text { la investigación e innovación de la } \\
\text { docencia. } \\
\text { desempeño de la docencia. } \\
\text { universidades en procesos de } \\
\text { construcción y dominio de las } \\
\text { competencias docentes más } \\
\text { pertinentes. } \\
\text { investigación para el mejor } \\
\text { dima de colaboración }\end{array}$ & $\begin{array}{c}\text {-Análisis del contenido del } \\
\text { programa. } \\
\text { - Comparación de programa } \\
\text { con otros similares de desarrollo } \\
\text { profesional del profesorado. } \\
\text { - Trabajo en equipo para } \\
\text { diseñar el programa para } \\
\text { dominar las competencias. } \\
\text { - Análisis de la calidad } \\
\text { formativa de las competencias } \\
\text { seleccionadas a alcanzar en el } \\
\text { programa. } \\
\text { - Contraste del programa } \\
\text { diseñado con modelos de } \\
\text { formación del profesorado } \\
\text { universitario. } \\
\text { - Transferencia de las } \\
\text { competencias pretendidas en el } \\
\text { programa a las necesidades } \\
\text { concretas en los procesos de } \\
\text { enseñanza-aprendizaje. }\end{array}$ & $\begin{array}{c}\text { - Elaboración de } \\
\text { programas de formación. } \\
\text {-Consolidación del mapa } \\
\text { de competencias más } \\
\text { valiosas para la docencia } \\
\text { universitaria. } \\
\text { - Diseño de estudios de } \\
\text { caso a realizar para el } \\
\text { dominio de las } \\
\text { competencias. } \\
\text { - Desarrollo de } \\
\text { actividades docentes } \\
\text { mediante una cultura de } \\
\text { colaboración. } \\
\text {-Determinación de las } \\
\text { secuencias de las tareas } \\
\text { como base para dominar las } \\
\text { competencias. } \\
\text {-Armonización entre } \\
\text { competencias y objetivos } \\
\text { para avanzar en su logro. }\end{array}$ \\
\hline
\end{tabular}


Evaluación de programas de formación de formadores y docentes: Estudio de caso.

\begin{tabular}{|c|c|c|}
\hline $\begin{array}{c}\text { Desarrollo del programa } \\
\text { (evaluación) }\end{array}$ & Métodos & Resultados \\
\hline $\begin{array}{l}\text { - Aplicación de estudios de } \\
\text { casos para dominar las } \\
\text { competencias docentes. } \\
\text { - Construcción por cada } \\
\text { docente del mapa de } \\
\text { competencias a dominar. } \\
\text { - Avance reflexivo, partiendo } \\
\text { de prácticas gratificantes en el } \\
\text { dominio de las competencias. } \\
\text { - Puesta en práctica: } \\
\text { - Planificación. } \\
\text { - Desempeño en la acción de } \\
\text { las competencias elegidas. } \\
\text { - Complementariedad en el } \\
\text { dominio del conjunto de } \\
\text { competencias docentes elegidas. }\end{array}$ & $\begin{array}{c}\text { - Estudio de casos. } \\
\text { - Trabajo en equipo. } \\
\text { - Encuestas (cuestionario). } \\
\text { - Grupos de discusión. } \\
\text { - Observación perseverante. } \\
\text { - Narrativas del proceso } \\
\quad \text { seguido. } \\
\text { - Aprendizaje basado en } \\
\text { problemas. } \\
\text { - Autoanálisis de la práctica: } \\
\text {-Realizar tareas para } \\
\text { avanzar en las competencias. } \\
\text {-Valorar las tareas } \\
\text { efectuadas en las clases. } \\
\text { - Cuadernos de campo } \\
\text { exponiendo el logro en cada } \\
\text { competencia docente. } \\
\text { escenas/tareas representativas } \\
\text { del dominio de las }\end{array}$ & $\begin{array}{c}\text {-Dominio de las } \\
\text { competencias seleccionadas. } \\
\text { - Configuración del } \\
\text { mapa de competencias } \\
\text { docentes necesitadas en la } \\
\text { práctica individual. } \\
\text { - Aparece en el mapa de } \\
\text { competencias elegidas por la } \\
\text { Universidad. } \\
\text { - Aplicación del método } \\
\text { de estudio de caso para } \\
\text { dominar las competencias } \\
\text { seleccionadas. } \\
\text { - Realizar la práctica } \\
\text { docente como un proceso de } \\
\text { investigación e innovación } \\
\text { para mejorar el dominio de } \\
\text { las competencias. }\end{array}$ \\
\hline
\end{tabular}

Tabla 4. Evaluación del programa-proyecto de innovación de formación del profesorado universitario para mejorar las competencias docentes. (Medina y cols, 2013). 


\section{Análisis de los resultados e impacto del programa.}

En coherencia con el modelo de evaluación aplicado al programa, se tendrán en cuenta los criterios de complejidad, pertinencia, calidad y repercusión en la implantación del EEES y las respectivas formas de los países participantes en su desarrollo, especialmente de Ecuador y México, básicas en la cooperación internacional y en el desempeño de los estudios de caso llevados a cabo.

La evaluación pondrá de manifiesto la pertinencia del programa para responder al momento de la actualización del profesorado implicado, a la necesaria cooperación interuniversitaria y al logro de un mapa de competencias, valorado en su aportación integral y en la relevancia de los grandes factores o agrupamientos de competencias, que representan los aspectos esenciales de:

- Planificación (destacada como singular y prioritaria).

- Puesta en acción de los procesos de planificación:

$\checkmark$ Tutoría.

$\checkmark$ Comunicación.

- Motivación.

- Metodología: diseño integración de medios.

- Evaluación.

$\checkmark \quad$ Identidad profesional, síntesis del conjunto de las desarrolladas y punto de vertebración de las siguientes.

- Desarrollo de competencias para la investigación y mejora integral de la educación universitaria y de los procesos de enseñanza -aprendizaje:

$\checkmark$ Investigación.

$\checkmark$ Innovación.

$\checkmark$ Pertenencia institucional.

$\checkmark$ Interculturalidad.

La evaluación se ha centrado en un estudio descriptivo -exploratorio, mediante la aplicación de la metodología integrada: cuestionario con puntuaciones de 1 a 6 , 
Evaluación de programas de formación de formadores y docentes: Estudio de caso.

preguntas abiertas grupos de discusión, orientados a la comprensión de los procesos de valoración y ponderación del sentido de cada competencia.

La evaluación de las competencias mencionadas, mediante una triple estimación:

- Puntuación en una escala de Likert de 1 a 6, alcanzando el conjunto un elevado peso, así, en la moda todos las competencias presentadas obtuvieron la máxima puntuación (6) y se mantiene este valor en la mediana para la mitad (6); planificación, comunicación, metodología, evaluación, innovación e identidad profesional superan la media con 5 puntos la totalidad, entre las que alcanza un mayor valor en ella, destacan:

\begin{tabular}{|c|c|}
\hline$\checkmark \quad$ Identidad profesional & $(5.61)$ \\
\hline$\checkmark \quad$ Planificación & $(5.44)$ \\
\hline Evaluación & $(5.43)$ \\
\hline Comunicación & $(5 \cdot 38)$ \\
\hline Metodología & $(5 \cdot 36)$ \\
\hline Integración de medios & $(5.20)$ \\
\hline
\end{tabular}

Y como contrapunto las que tienen menor puntuación son:

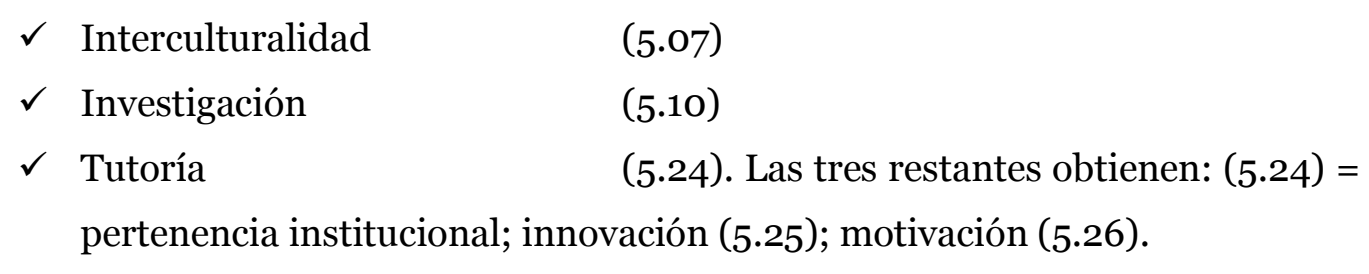

La estimación alcanzada del cuestionario es alta, se sitúa en el padrón superior.

Se procedió a la evaluación más y de carácter ordinario, al solicitarse a los cerca de $600 /(591)$, docentes que respondieron al cuestionario, que establecieran la prioridad, considerando la que a su juicio debiera ocupar el primer rango, hasta el $12^{\circ}$, la jerarquía obtenida, mediante un sistema de contrastes individuales, seleccionando las 404 respuestas que tales docentes han expresado y que se han considerado válidas.

El ranking se ha establecido del siguiente modo:

- Planificación

- Metodología 
- Integración de medios

- Investigación

- Motivación

- Innovación

- Identidad profesional

- Evaluación

- Comunicación

- Tutoría

- Pertenencia institucional

- Intercultural

Las modalidades evaluativas evidencian una adecuada coincidencia en algunas y autonomía de valoración y reconocimiento en la ordenación:

- Planificación

- Metodología

- Integración de medios

Estas competencias obtuvieron mayores valores en las medias, moda y mediana.

Así mismo, las competencias, en este orden de: intercultural $\left(12^{\mathrm{a}}\right)$, pertenencia institucional $\left(11^{\mathrm{a}}\right)$, tutoría $\left(10^{\mathrm{a}}\right)$; se destacan por mantener una ordenación que las sitúa al final de la escala, aspectos que se matizan, especialmente la puntuación que el profesorado de UNED, otorga a la competencia tutorial, comunicación, integración de medios, metodología, consideradas con un nivel más destacado y relevante que lo ha sido para el profesorado de las modalidades presenciales. (UNED -Madrid y ESPE Quito), coinciden en su especificidad a distancia.

La evaluación cualitativa mediante el programa de minería de datos, nos permite identificar los términos y su porcentaje, agrupados por las competencias.

Los textos expresados por los encuestados evidencian en porcentajes y número de términos (Medina, y cols, 2013, 247), una destacada serie de tales respuestas: 
- Integración de medios

- Metodología

- Identidad profesional

- Investigación

- Evaluación

- Planificación

- Pertenencia institucional

- Tutoría

- Motivación

- Comunicación

- Intercultural

- Innovación

Núm. $\quad \%$

$\begin{array}{rr}213 & 15.80 \\ 183 & 13.60 \\ 170 & 12.60 \\ 147 & 10.90 \\ 114 & 8.50 \\ 111 & 8.20 \\ 100 & 7.40 \\ 89 & 6.60 \\ 86 & 6.40 \\ 64 & 4.70 \\ 46 & 3.40 \\ 25 & 1.90\end{array}$

Esta presentación de conceptos referidos al interés mostrado y a la presencia de las diversas competencias en los textos evidencia, que se sitúa en el mayor interés del profesorado, en una clara coincidencia con la ordenación presentada anteriormente:

- Integración de medios.

- Metodología

- Investigación.

Cambiando de orden planificación e identidad profesional, retrasándose la presencia de la primera y ocupando el tercer lugar la identidad profesional.

Estas modalidades de evaluación, vuelven a resituar de manera similar y en lugares últimos las competencias de: interculturalidad y comunicación, aunque son relevantes para promover el diálogo y encuentro con y entre culturas.

La evaluación de los resultados y el impacto de estas competencias han sido elevados, sirviendo de base en todas las universidades para la preparación del profesorado, con especial incidencia en grupos consolidados de docentes en la Universidad ESPE- Quito.

Esta universidad y sus directivos sistema distancia han valorado el impacto del programa en la cultura universitaria y subrayado el papel de la formación del 
profesorado en el mapa de competencias, integrando en su práctica acciones y tareas propuestas, junto a Jornadas ad hoc, de colaboración intensa entre UNED y ESPE.

Se ha de continuar evaluando (meta-evaluación) el impacto del programa de formación y dominio de las competencias docentes, apoyado en el diseño y desarrollo de tareas relevantes.

Se realiza esta valoración mediante el juicio de la dirección del modelo de educación a distancia, la autoevaluación de las prácticas innovadoras, que mejoran el dominio de las competencias y los grupos de discusión.

Se considera que el modelo de competencias docentes y su proyección en las prácticas educativas es una aportación pertinente al desarrollo profesional del profesorado universitario, conscientes de que ha de completarse con un proceso de transformación de la acción educativa desempeñando las prácticas, con gran autonomía, trabajo en equipo y toma de decisiones artísticas.

El programa ha provocado un intenso impacto, al menos, los cincuenta docentes implicados en las jornadas de desarrollo profesional, dado que constituyeron su propio mapa de formación de las competencias docentes, aplicaron actividades más pertinentes para su dominio y llevaron a cabo prácticas creativas de mejora del pensamiento y estilo docente en sus aulas, de modo individual y en pequeños grupos.

\section{Propuestas de mejora.}

El programa diseñado y aplicado en varias universidades, mediante el método de estudio de caso, se ha valorado (autoevaluaciones, informes de directos y grupos de discusión) y mejorado con nuevos proyectos en curso y aplicado a éstos el modelo ROI (Medina Domínguez, 2012), que evidencia la eficiencia de los recursos a la formación, constatando que se ha de convertir en una óptima inversión, aplicada al desarrollo de las organizaciones.

El programa mejorará al incrementar la relación entre los procesos de investigación e innovación de la docencia, realizados por el profesorado participante, constituido en equipo de colaboración y construcción de la conciencia profesional. 
La elaboración del mapa de competencias emergido y altamente valorado por el profesorado de las cinco universidades implicadas podrá ir adaptándose y afianzándose en función de las necesidades, de la misión y del proyecto formativo de cada una, a la vez que los docentes y equipos seleccionarán las más pertinentes para su contexto y expectativas, creándose un clima de mejora de los procesos de enseñanza-aprendizaje y consolidando una línea de desarrollo profesional del profesorado, ampliada con las ofertas de otras universidades implicadas en la Red RIAICES, de ámbito Iberoamericano.

El programa se ha de mejorar con el empleo de la metodología heurística y didáctica, avanzándose en un estilo de verdadera búsqueda y consolidación de modelos que orienten y fundamenten las prácticas de enseñanza-aprendizaje a trabajar en cada aula, facultades y universidades.

La formación docente ha de situarse en un lugar prioritario y devolver al profesorado universitario la responsabilidad de construir su línea, creativa y abierta, que sirva de base para comprender e innovar con base en la investigación de la docencia, ligada a la transformación de la universidad de la que forma parte; se han de apoyar las acciones educativas, el diálogo y en encuentro entre las culturas presentes en la institución, afianzando la competencia intercultural.

Las mejoras en el programa de formación han de darse en el fomento de las competencias docentes y en desempeño de prácticas artísticas, que conviertan la tarea docente del profesorado en problemas relevantes desde los que aprender a tomar las decisiones más adecuadas para optimizar la docencia, avanzar en tales competencias mediante los estudio de casos (Hamilton y Corbett-Whittier, 2013), aplicando las modalidades de casos: Reflexivo y colaborativo, completados con el longitudinal, afianzando el conocimiento y la comprensión profunda de lo que acontece en cada aula, red docente,, ambiente virtual en los que el docente el docente y equipos compartan procesos de aprendizaje fecundos, loa analicen como problemas relevantes, resolviéndolos mediante la combinación entre casos reflexivos y singulares, con un análisis meticuloso a lo largo de, al menos, un bienio aprovechando la permanencia en el tiempo del estudio intenso y prolongado. 


\section{Discusión y conclusiones.}

La evaluación del programa de formación de formadores es coherente con los modelos presentados por Martínez (2010) y Pérez, (2006) y los hallazgos acerca de la modalidad del programa y de sus componentes que se confirman en investigaciones como: Stufflebeam y Shinkfield (2007), Stake (2013), Fernández (1996), Medina y Domínguez (2008).

El impacto del programa de formación de formadores en el desarrollo de las instituciones y de sus participantes se confirma en los diferentes hallazgos, constatando que la mejora de la cultura de las instituciones y de todos sus miembros es la mayor garantía para avanzar en las prácticas innovadoras y en la calidad de los procesos productivos.

Los formadores son los colaboradores adecuados para la transformación de las instituciones, ya que vislumbran las necesidades futuras de las personas de la organización.

Fernández y cols (2000), destacan la especialización de los mismos y su incidencia en la transformación de las organizaciones. Éste programa que valoramos fue una incursión en facilitación de un modelo centrado en la complementariedad entre el autoaprendizaje, y apoyado en la propia experiencia, la colaboración entre pares y equipos y la integración de la investigación en las tareas formativas, que se proyectan en una línea de pleno desarrollo profesional, concretado en procesos de internacionalización de la formación de formadores (Tejada, 2013).

La visión actual evidencia la necesidad de la capacitación de los formadores de formadores, prioritariamente y del profesorado universitario, coincidiendo con trabajos anteriores del mismo equipo (Medina, 2009), y opciones transformadoras, que han aportado ideas creativas al modelo de formación del profesorado universitario basado en competencias, consolidándose esta línea en coherencia con las investigaciones previas de (Villar, 2004; Zabalza, 2006; De la Hoz, 2010; Esteban y Menjívar de Borbón, 2011), avanzando una línea de formación del profesorado universitario coherente con las claves del desarrollo profesional continuo y la estimulación de acciones institucionales de las universidades, que mejoren los procesos y las claves de la organización, por excelencia, orientada a la capacitación y preparación creativa de los 
Evaluación de programas de formación de formadores y docentes: Estudio de caso.

profesionales más innovadores de la sociedad, las empresas y cualquier entidad generadora de productos y servicios de calidad.

Se aporta en este programa de formación el dominio de las competencias, sintetizadas en un mapa de armonización y jerarquización, a la vez que se destaca el conjunto más creativo de tareas a aplicar para conseguir el óptimo desarrollo de las mismas en las más complejas y relevante situaciones de formación, aprovechando las experiencias vividas por el profesorado en la diversidad de ambientes de enseñanzaaprendizaje.

Las conclusiones evidencian el logro de los objetivos formativos pretendidos y el proceso de evaluación, la pertinencia de los programas para mejorar la formación.

Los estudios de caso de algunos proyectos relevantes realizados, han puesto de manifiesto que:

La evaluación de los programas de formación de docentes constituye una línea fecunda para la mejora de tales programas y un camino imprescindible para avanzar en el diseño, desarrollo y meta-evaluación de los mismos.

La formación mediante la síntesis del autoaprendizaje experiencial, colaborativo y la investigación desde la práctica, apoyada en modelos teóricos -aplicados, es esencial para fundamentar la capacitación y el dominio de competencias genéricas y profesionales de formadores y docentes universitarios.

El programa de formación de formadores ha configurado una nueva visión profesional de los implicados, así como una adecuación el empleo de los ordenadores y de las prácticas a realizar a lo largo de la vida. El trabajo realizado es una innovación de los procesos de investigación del programa y aporta un modelo de formación de formadores integrador, de generación de procesos de transformación continua apoyados en una línea de búsqueda y de desarrollo profesional.

La metodología aplicada es la complementariedad de métodos cuantitativos y cualitativos, generando un estilo de indagación coherente con los grandes retos de la formación del profesorado en periodos de complejidad y de permanentes cambios. 
La formación del profesorado orientada al dominio de competencias docentes es reconocida una línea necesaria y altamente valorada por el profesorado universitario, alcanzando una media de 5.23, en un valor máximo de 6 , y una moda de 6 (12 competencias elegidas).

Las competencias se han configurado en un mapa de 12 y estimadas por una gran muestra de casi 600 docentes universitarios, los resultados se han sometido a un análisis factoriales, que se sintetiza en tres grandes factores:

- Primer factor, la competencia de planificación, considerada esencial para el desarrollo de la docencia y focalizadora de las restantes.

- Segundo factor, competencias de desarrollo de los procesos de enseñanza aprendizaje, aplicación de la planificación y formado por 6 más una.

$\checkmark \quad$ Comunicación, tutorial y motivación.

$\checkmark \quad$ Metodología de diseño -integración de medios.

$\checkmark \quad$ Evaluación.

$\checkmark \quad$ Identidad profesional, considerada una meta competencia y de integración con las restantes.

- Tercer factor, innovación y transformación de los procesos de enseñanza aprendizaje, constituido por cuatro:

$\checkmark \quad$ investigación e innovación.

$\checkmark \quad$ Pertenencia institucional en intercultural.

La evaluación del programa ha aportado el significado de la calidad del proceso de formación en sí, en nuestro caso, el conjunto de competencias docentes necesarias para el desempeño de las tareas formativas en los centros universitarios, completada con la selección de las tareas más pertinentes para que cada docente y las instituciones universitarias diseñen programas que faciliten la formación continua del profesorado universitario, protagonistas destacados de los múltiples retos de la transformación de las universidades y las empresas.

Se han de atender los cambios y creativas profesiones, que requieren ambientes y escenarios universales en los que han de participar los nuevos graduados universitarios. 
Evaluación de programas de formación de formadores y docentes: Estudio de caso.

Las tareas innovadoras para dominar las competencias han de ser aplicadas en mayor intensidad, valoradas y contrastadas en la acción por nuevos equipos de docentes, generando de esta línea una taxonomía artístico -normativa, que sitúe a cada docente y equipo las más valiosas, que su peculiaridad formativa, su institución y los estudiantes le demanden.

La investigación educativa está estrechamente ligada al diseño de programas de formación del profesorado para que la desarrollen y transformen desde el desempeño de sus prácticas innovadoras, conscientes del papel de los métodos heurístico didácticos. Se requiere una línea de investigación educativa (Creswell, 2008), que integre métodos cuanti y cualitativos, mediante una intensa colección de datos, derivados de la calidad del programa de formación y su impacto en los docentes formados, ampliados con el alto análisis y comprensión de la relevancia de tal programa en el desarrollo profesional continuo y en la identidad con la profesión de docente universitario, sintetizando la información derivada de pequeños casos de individuos o de escenarios pertinentes.

Se completa el análisis de abundantes datos estadísticos, con la lectura atenta de las fases, textos para descubrir el significado de los hallazgos encontrados.

La evaluación del impacto formativo de un programa de actualización de docentes y de redes de innovación de la docencia ha de tener un segundo momento de lectura de aquellos, al valorar las mejoras reales alcanzadas por los estudiantes en los procesos de aprendizaje, en el dominio de las competencias discentes en los procesos interactivos de la vida de los estudiantes, quienes han de superar las dificultades y lograr un proceso de profesionalización que se proyecte en su trabajo en las organizaciones, en su participación en las empresas y en el compromiso expreso con los más amplios y complejos escenarios de un mundo globalizado y con unas instituciones e innecesaria y continua transformación. 


\section{Referencias Bibliográficas}

Creswell, J.W. (2008). Educational research. Ohio: Pearson/Prentice Hall.

De la Hoz, G (2010). Los médicos y la educación médica. Barranquilla: Universidad Libre.

DeVries, Van de Grift \& Jansen, 2013: Teachers' beliefs and continuing professional development. Journal of Educational Administration, Vol. 51 Iss: 2, pp. 213-231.

Domínguez, M.C. (1997) (Ed). La formación para el desarrollo de las comarcas. Madrid: UNED.

Esteban, M.R. \& Menjívar de Borbón, S.V. (2011). Una mirada internacional a las competencias docentes universitarias. Barcelona: Octaedro.

Fernández, A. (1996). El formador. Competencias profesionales para la innovación. En J. Gairín, A. Fernández, J. Tejada y A. Navío, Formación para el empleo. (pp.171218). Barcelona: NEO-3.

Fernández, A., Tejada, J. Jurado, P., Navío, A. \& Ruiz, C. (2000). Formacion del formador profesional y ocupacional. Barcelona: Octaedro.

González, A.P. (2013). La formación para el trabajo: perspectivas de futuro. En C. Ruiz, A. Navío, M. Fandos y P. Olmos. Formación para el trabajo en tiempo de crisis: balance y prospectiva. (pp. 51-58). Tarragona-Barcelona; Grupo CIFO: Tornapunta Ediciones.

Hamilton L. \& Corbett-Whittier, C. (2013). Using case study in education research. London: SAGE.

Ibáñez, J.A. et al. (1998). La profesión docente: diagnóstico del sistema educativo. Madrid: INCE (MEC).

Ibáñez, A. y cols. (2008). Interculturalidad, formación del profesorado y educación. Madrid: Pearson.

Informe PISA-OCDE (2003. Aprender para el mundo del mañana. Madrid: Santillana. 
Evaluación de programas de formación de formadores y docentes: Estudio de caso.

Levin, H.M. \& McEwan, P.J. (2003). Cost-effectiveness analysis as an evaluation tool. En T. Kellaghan, D. L. Stufflebeam y L.A. Wingate. International handbook of educational evaluation, I. (pp. 125-152). Dordrecht/Boston: Kluwer Academic Publishers.

Labeaga, J.M. \& Ramiro, A. (2013). Rendición de cuentas con transparencia en el sector público: ¿Otra vez lo que el viento se llevó? Revista de Evaluación de Programas y Políticas Públicas, (1), 137-168.

Marcelo, C. (2013). Evaluación del desarrollo profesional docente. Ed. Davinci.

Martínez, C. (2010). Técnicas e instrumentos de recogida y análisis de datos. Madrid: UNED.

Martínez, C. (2011). Evaluación de programas: Modelos y procedimientos. Madrid: UNED.

Mas, O. y cols. (2013). Funciones y competencias en la docencia universitaria. Ed: Síntesis.

Medina, A. Pérez, I. y Campos, B. (2014). Elaboración de planes y programas de formación del profesorado en didácticas específicas. Madrid: UNED

Medina, A. y Cols. (2013) (Coord.). Formación del profesorado. Actividades innovadoras para el dominio de las competencias docentes. Madrid: Ramón Areces.

Medina, A., De la Herrán, A. y Domínguez, M.C. (2013). , Fronteras en la investigación de la didáctica. Madrid: UNED, e-book.

Medina, A. (2011). Innovación de la educación y de la docencia. Madrid: Ramón Areces.

Medina, A. (2009) (Ed.). Formación y desarrollo de las competencias básicas. Madrid: Universitas. Traducción portugués (2010) IPEX, Curitiba.

Medina, A. y Domínguez, M.C. (2008). Formación base del desarrollo de las comarcas. Madrid: Universitas.

Medina, A. (2003) (Ed.). Evaluación de la calidad de las instituciones universitarias. Madrid: Universitas. 
Medina, A. y Rodríguez, A. (1998). Un enfoque interdisciplinar en la formación de los maestros. Madrid: Narcea.

Medina, A. y Villar, L.M. (1995) (Eds.). Evaluación de programas, centros y profesorado. Madrid: Universitas.

Medina, A. y Domínguez, M.C. (1991). Formación de formadores para el empleo de Tic. Proyecto Fondo Social Europeo-UNED.

Medina Domínguez, C. (2012). La empresa y la inversión en formación: El ROI. Madrid: Universitas.

Pérez, R. (2006). Evaluación de programas educativos. Madrid: La Muralla.

Ruiz, A. y Medina, A. (2014). Modelo didáctico intercultural en el contexto afrocolombiano: la etnoeducación y la cátedra de estudios afrocolombianos. Indivisa, Boletín de Estudios e Investigaciones. Madrid: La Salle.

Scriven, M. (2003). Evaluation in the new millennium: The transdisciplinary vision. In S. I. Donaldson \& M. Scriven (Eds.), Evaluating social programs and problems: Visions for the millennium). Mahwah, NJ: Lawrence Erlbaum Associates. 19-42.

Stake, R. E. (2013). Evaluación comprensiva y evaluación basada en estándares. Barcelona: Grao.

Stufflebeam, D.L. (2003). The CIPP. Model for Evaluation. En T. Kellaghan, D.L. Stufflebeam y L.A. Wingate, International handbook of educational evaluation, I. Dordrecht/Boston, Kluwer Academic Publishers, 31-62.

Stufflebeam, D. y Shinkfield, A. (2007). Evaluation, theory, models and applications. London: John Wiley \& Sons.

Tejada, J. (2013). El formador y su formación: de la pre-formación a la profesionalización. Balance y prospectiva. En C. Ruiz, A. Navío, M. Fandos y P. Olmos, Formación para el trabajo en tiempo de crisis: Balance y prospectiva. Tarragona-Barcelona; Grupo CIFO: Tornapunta Ediciones. 141-159.

Tiana, A. (2013). La IEA y la evaluación internacional de los resultados de la educación: medio siglo de trabajos e investigaciones. En J. Vergara, E. Gavari y M.J. García 
Evaluación de programas de formación de formadores y docentes: Estudio de caso.

(Coords.). Conversaciones con un maestro: homenaje a García Garrido, J.L. Madrid: Ediciones Académicas. 741-752.

Villar, L.M. (2004) (Ed.). Programa para la mejora de la docencia universitaria. Madrid: Pearson Educación.

Yarbrough, D et al. (1994). The program evaluation standard (2 ${ }^{\text {nd }}$ edition). Joint Committee on Standards for Evaluation. Sage publications.

Zabalza, M. A. (2006). Competencias docentes del profesorado universitario. Calidad y desarrollo profesional. Madrid: Narcea. 